\title{
Neoconstitucionalismo ambiental y derechos de la Naturaleza en el marco del nuevo constitucionalismo latinoamericano: El caso de Colombia
}

\author{
Environmental neoconstitutionalism and Nature's rights in the framework of the new latin \\ american constitutionalism: The case of Colombia
}

\author{
LILIANA ESTUPIÑÁN ACHURY* \\ Profesora de Régimen Territorial y Derecho Constitucional \\ Universidad Libre (Colombia) \\ lilianaea@hotmail.com \\ https://orcid.org/0000-0001-5233-6516
}

\begin{abstract}
Resumen: A pesar de no haberse consagrado un título o capítulo especial sobre los derechos de la naturaleza o la naturaleza como sujeto de protección jurídica en la Constitución Política de Colombia de 1991, algunos principios, derechos de diversas clases, consagraciones especiales o explícitas en materia de derecho ambiental y el bloque de constitucionalidad han permitido la construcción real del concepto que se puede visualizar en diversos movimientos sociales, ambientalistas y de protección de la Madre Tierra, pactos sociales y políticos de diversos actores territoriales y nacionales, y pronunciamientos jurisprudenciales "heréticos", para la doctrina tradicional, que incluso han permitido pensar en una reforma constitucional para insertar esta novedosa categoría en el Texto Político de 1991.

Abstract: In spite of not having consecrated a special title or chapter on the rights of nature or nature as subject of juridical protection in Colombian Political Constitution of 1991, some principles rights of diverse types, special or explicit consecrations in matters of environmental law and the block of constitutionality have allowed the real construction of the concept that can be visualized in diverse social movements, environmentalists and protection of mother earth, social and political pacts of various territorial and national actors, and jurisprudential pronouncements "heretical", for the traditional doctrine, which have even allowed to think of a constitutional reform to insert this novel category in the Political Text of 1991.
\end{abstract}

Recepción: 11/05/2020

Aceptación: 22/05/2020

Cómo citar este trabajo: ESTUPIÑÁN ACHURY, Liliana, "Neoconstitucionalismo ambiental y derechos de la Naturaleza en el marco del nuevo constitucionalismo latinoamericano: El caso de Colombia", Revista de Estudios Jurídicos y Criminológicos, ISSN-e: 2660-7964, nº 1, Universidad de Cádiz, 2020, pp. 127-143, DOI: https://doi.org/10.25267/REJUCRIM.2020.i1.6

* Resultado parcial del proyecto de investigación y cooperación: Erasmus OPT-IN en paz, interculturalidad y derechos de la naturaleza. Proyecto financiado por la Unión Europea y adscrito al Grupo de Investigación Estudios Constitucionales y de la Paz, de la Facultad de Derecho de la Universidad Libre - Sede Principal. Resultado de la fase de investigación posdoctoral en Derecho Constitucional, realizada durante el año 2019 en la Universidad de Valencia bajo la tutoría de los profesores Rubén Martínez Dalmau y Roberto Viciano Pastor. Capítulo publicado en la obra colectiva "La naturaleza como sujeto de derechos en el constitucionalismo democrático". 
Palabras claves: derechos de la naturaleza, ecología capitalista, nuevo constitucionalismo latinoamericano, constitucionalismo andino, Colombia, Ecuador, Bolivia y derecho ambiental.

Keywords: rights of nature, capitalist ecology, new latin american constitutionalism, andean constitutionalism, Colombia, Ecuador, Bolivia and environmental law.

Sumario: 1. LO NUEVO ES LO ANCESTRAL, LO QUE NUNCA DEJARON PERVIVIR LAS LÓGICAS BLANCAS Y EUROCÉNTRICAS. 2. TRANSFORMACIÓN EPISTEMOLÓGICA Y REDESCUBRIMIENTO DE LO ANCESTRAL EN LAS NUEVAS CONSTITUCIONES O LECTURAS CONSTITUCIONALES. 3. LA TÍMIDA APUESTA AMBIENTAL DE LA CONSTITUCIÓN POLÍTICA DE 1991, EN CLAVE DE NEOCONSTITUCIONALISMO. 4. CON PEDAZOS DE ESTRELLAS INVENTAMOS MUNDOS. LA CONSTRUCCIÓN DEL DERECHO DE LA NATURALEZA EN COLOMBIA. 5. BIBLIOGRAFÍA.

\section{LO NUEVO ES LO ANCESTRAL, LO QUE NUNCA DEJARON PERVIVIR LAS LÓGICAS BLANCAS Y EUROCÉNTRICAS}

Un pensamiento milenario se ha convertido en paradigma constitucional moderno para algunos países de América Latina y de otros lugares del mundo. Pensamiento arrebatado por siglos de homogeneidad, colonialidad y sujeción ideológica. A pesar de ello, la unidad entre el hombre y la Madre Tierra o la naturaleza ha estado presente en la mayoría de las culturas indígenas latinoamericanas. Dios era y es la propia naturaleza. Ni sujeto ni objeto; lo era todo y lo es todo. Los hombres, apenas, una parte ínfima del cosmos.

Algunos grupos étnicos lograron cuidar su filosofía y pensamiento, se arraigaron en sus territorios ancestrales y lograron conservar sus instituciones y formas de ver el mundo, la justicia y la cultura, muy a pesar de la violencia a la que fueron sometidos, de las imposiciones religiosas, ideológicas, sociales y económicas de la colonialidad y el imperio.

Su forma natural de ver el mundo pervivió durante varias centurias y afloró en el siglo XX ante los diversos conflictos, las luchas por sus territorios, la pretendida homogeneización de Occidente, la cruz y la biblia y el modelo de desarrollo que ha arrasado con ríos, bosques, selvas, montañas, sitios sagrados, mares, aire, tierra y todo.

Aun los más occidentalizados, buscaron en su ADN cultural la resistencia y las formas decentes de relación entre el hombre y la naturaleza, como un todo. Movimientos sociales, políticos, culturales se han observado en esta línea. Poco a poco, han participado del poder popular y soberano en asambleas constituyentes y han dejado su impronta en la forma de concebir el mundo en los textos constitucionales. Unos menos arriesgados que otros, pero, al fin y al cabo, toda una transformación epistemológica que promete consagrarse en las próximas décadas o siglos. 
Así, las constituciones blancas, o de simple élite, mutaron en algunos lugares del mundo e incluyeron, unas en mayor medida que otras, algunos principios e incluso cosmovisiones que dieron lugar a una trasformación que ya se venía gestando en los territorios.

En otros países, con constituciones liberales y de corte antropocéntrico, tímidas en la consagración de principios ancestrales o de enfoque ambiental, serán los jueces, los operadores jurídicos, las comunidades, los líderes sociales y ambientales los autores o gestores de nuevas interpretaciones y polémicas lecturas sobre la relación entre los hombres y la naturaleza, o mejor, sobre la dominación de la naturaleza por la soberbia del hombre.

\section{TRANSFORMACIÓN EPISTEMOLÓGICA Y REDESCUBRIMIENTO DE LO ANCESTRAL EN LAS NUEVAS CONSTITUCIONES O LECTURAS CONSTITUCIONALES}

Sin duda, el caso colombiano es emblemático frente a esta última perspectiva. Aunque ligado al denominado enfoque ambiental, conforme se lee en su Texto Político de 1991. Muy a tono con las preocupaciones nacionales e internacionales sobre el impacto del capitalismo en la tierra y sus nefastas consecuencias.

Esta Constitución se identifica como ecológica, marcadamente antropocéntrica, pero fundamental para la construcción normativa e incluso jurisprudencial sobre el tema. En este último punto, es evidente que Colombia ha construido unos fallos o unas sentencias emblemáticas que hoy son citadas en diversas partes del mundo. A tal punto que se habla de una posible reforma constitucional para insertar un capítulo en la Constitución Política sobre los derechos de la naturaleza ("Buscan reformar la Constitución para declarar a la naturaleza como sujeto de derechos", 2019). La transformación va en camino, las comunidades y los jueces han hecho una lectura que va más allá del tradicional derecho ambiental. En este aspecto, se reitera el papel de los actores internacionales y nacionales en hacer más explícito o agresivo en los textos constitucionales el enfoque ambiental creado bajo las lógicas occidentales o de capitalismo ecológico, la misma idea para las construcciones legislativas y jurisprudenciales.

Como se observa, en este tema confluyen varios actores. Por una parte, sociedades marcadamente indígenas, abandonadas por siglos y dominadas por lógicas blancas o europeas, que lograron a finales del siglo XX y comienzos del siglo XXI tener un espacio digno en los procesos constitucionales que se gestaron en Ecuador y en Bolivia. Incluso, una mínima participación, pero fundamental, en el marco de la Asamblea Nacional Constituyente de $1991^{1}$. Sus Estados, historias y configuraciones culturales, nacionales y humanas dieron lugar al inicio

\footnotetext{
${ }^{1}$ LONDOÑO, B., (s.f.) señala: “Con la elección de dos constituyentes indígenas, Lorenzo Muelas (20.083 votos) y Francisco Rojas Birry (25.880 votos), se empezó a reconocer una realidad que hasta entonces había sido invisible para nuestro país: su evidente carácter multiétnico y pluricultural. La fuerza y el empuje de estos dos constituyentes fue evidente y marcó avances significativos en la Constitución de 1991. Su influencia fue notoria en tres aspectos que deben señalarse: 1. el ordenamiento territorial; 2. la apertura de espacios políticos y sociales de participación para los indígenas y los demás grupos étnicos, en especial la circunscripción especial indígena para el Senado y la circunscripción especial para los grupos étnicos; 3. el reconocimiento del carácter multiétnico y pluricultural de nuestro país y la garantía a derechos territoriales y culturales de los indígenas en la nueva Constitución”.
} 
del constitucionalismo plural en América Latina junto con las correspondientes consecuencias que ello implica. Por otra parte, comunidades, actores nacionales e internacionales en clave de protección de la tierra, los territorios, consulta previa y popular, protesta social y las tensiones propias que suscita el modelo extractivista y de consumo que no tiene corazón verde.

Tanto Ecuador como Bolivia permiten una nueva lectura en clave de pluralismo jurídico, pluralismo constitucional, plurinacionalismo, plurietnias, interculturalidad, diversidad, pensamiento complejo e inclusivo ${ }^{2}$. Nuevos principios, nuevas lecturas. Aun así, estos dos procesos constitucionales presentan en sus textos y en sus prácticas significativas diferencias. Por ejemplo, en materia de consagración de derechos de la naturaleza, la explícita mención en la Constitución ecuatoriana del año 2008 (Capítulo séptimo del Título II), única apuesta de esta clase en el mundo, o el desarrollo legislativo del caso boliviano (Ley 300/2012 -Ley Marco de la Madre Tierra y Desarrollo Integral para Vivir Bien-) a partir de los principios y enfoques consagrados en su Texto Político. Su concreción ha sido también diferente y compleja, muy marcada por el enfoque extractivista que también ha sido desarrollado por los gobiernos de centro o de izquierda en América Latina.

En general, todas estas nuevas construcciones epistemológicas y constitucionales no fueron borrón y cuenta nueva; más bien el cruce de las viejas instituciones, liberales individuales y sociales, con las necesidades y cosmovisiones ancestrales. Las miradas ancestrales, la costumbre, las formas políticas y de relacionarse con el territorio y la naturaleza ya existían y se resistían a morir, a pesar de la embestida colonial y del movimiento hegemónico del constitucionalismo liberal.

Varios de los capítulos que reposan en esta publicación hacen referencia a los momentos preconstitucionales, constitucionales y posconstitucionales que se vivieron en Ecuador y Bolivia. Hasta los juristas más tradicionales han tenido que volcar su mirada a las formas "excéntricas", para ellos, y ancestrales que han adoptado las nuevas constituciones y su cruce con las instituciones liberales gestadas durante siglos tanto en Europa como en Estados Unidos. Las categorías tradicionales de formas de Estado, gobierno, derechos, tribunales constitucionales, etc., han mutado, se han cruzado, han sido objeto de mestizaje y de nueva construcción. El mismo caso para el constitucionalismo ambiental que ha tenido que conciliar con líneas más radicales en materia de protección de la naturaleza (textos políticos con categorías tradicionales y radicales, compleja hibridación).

Del viejo Estado nación a la lógica plurinacional; de Estado unitario o Estado regional a "Estado Unitario Social de Derecho Plurinacional Comunitario, libre, independiente, soberano, democrático, intercultural, descentralizado y con autonomías" (caso de Bolivia). O, como fue llamado por Ecuador: "Estado constitucional de derechos y justicia, social, democrático,

${ }^{2}$ WOLKMER, A., Pluralismo jurídico fundamentos de una nueva cultura del derecho, $2^{\mathrm{a}}$ ed. Madrid: Dykinson, 2018. 
soberano, independiente, unitario, intercultural, plurinacional y laico". Bajo cualquier mirada, esta clase de identificaciones trastocan el derecho constitucional tradicional ${ }^{3}$.

De los principios de dignidad, unidad, igualdad, inclusión, libertad, solidaridad, reciprocidad, respeto, armonía, equilibrio, igualdad de oportunidades, equidad social y de género, bienestar común, responsabilidad, justicia social, distribución y redistribución, que aún se invocan en dichos textos constitucionales (Constitución de Bolivia), propios del constitucionalismo liberal y social, a los principios de "ama qhilla, ama llulla, ama suwa (no seas flojo, no seas mentiroso ni seas ladrón), suma qamaña (vivir bien), ñandereko (vida armoniosa), teko kavi (vida buena), ivi mararei (tierra sin mal) y qhapaj ñan (camino o vida noble)" (Constitución de Bolivia).

En la misma orientación, la consagración del principio del buen vivir de la Constitución ecuatoriana, el derecho humano al agua como fundamental e irrenunciable, la soberanía alimentaria, sumak kawsay, identidad cultural, consulta previa, libre e informada y todo un capítulo de reconocimiento de derechos de la naturaleza o Pacha Mama, reconocida como el espacio en donde "se reproduce y realiza la vida (y el cual tiene derecho a que se respete integralmente su existencia y el mantenimiento y) regeneración de sus ciclos vitales, estructura, funciones y proceso evolutivos" (Constitución de Ecuador), así como a la restauración y el principio de precaución. Cruce de diversas formas de entender la naturaleza y el derecho ambiental.

También, para el caso de Ecuador, la consagración de un sistema económico social y solidario, el ser humano como sujeto y fin en una relación dinámica entre sociedad, Estado y mercado, todo en armonía con la naturaleza y el buen vivir. Buenos propósitos que en la práctica han sucumbido ante el modelo neoliberal y el extractivismo, aun así, no menos importantes y necesarios.

Los preámbulos de estas constituciones, toda una poesía milenaria hecha política, hablan por sí solos de las tensiones entre las diversas formas de Estado, de gobierno, de principios, de valores, de derechos, de modelos económicos, de nacionalidades, entre otros temas que perviven de diferente forma en estos textos políticos. Lo nuevo era lo ancestral, lo que nunca tuvo respeto ante la homogeneidad de la dominación. Lo que se resistió a morir.

Estos dos preámbulos lo dicen todo: marcan la filosofía de los textos constitucionales de 2008 y 2009. Cruce de tradiciones constitucionales, pero resistencia, decolonización y pervivencia del pensamiento indígena y plural de estos países. Madre Tierra, pacha mama y consagración de los derechos de la naturaleza transforman poco a poco el discurso occidental del derecho ambiental, aun así, estas categorías conviven.

Preámbulo de la Constitución de Ecuador del año 2008:

\footnotetext{
3 PAVANI, G.; y ESTUPIÑÁN ACHURY, L., "Mutaciones del Estado Unitario en América Latina. Nuevos Rasgos Metodológicos para el Estudio de los Procesos de Descentralización”, Plurinacionalismo y Centralismo: Tensiones del Estado Unitario en América Latina (ed. Giorgia Pavani y Liliana Estupiñán Achury) Bogotá: Ediciones Nueva Jurídica, 2017, págs. 101-159.
} 
NOSOTRAS Y NOSOTROS, el pueblo soberano del Ecuador

RECONOCIENDO nuestras raices milenarias, forjadas por mujeres y hombres de distintos pueblos,

CELEBRANDO a la naturaleza, la Pacha Mama, de la que somos parte y que es vital para nuestra existencia,

INVOCANDO el nombre de Dios y reconociendo nuestras diversas formas de religiosidad y espiritualidad,

APELANDO a la sabiduría de todas las culturas que nos enriquecen como sociedad,

COMO HEREDEROS de las luchas sociales de liberación frente a todas las formas de dominación y colonialismo,

$Y$ con un profundo compromiso con el presente y el futuro,

\section{Decidimos construir}

Una nueva forma de convivencia ciudadana, en diversidad y armonía con la naturaleza, para alcanzar el buen vivir, el sumak kawsay;

Una sociedad que respeta, en todas sus dimensiones, la dignidad de las personas y las colectividades;

Un país democrático, comprometido con la integración latinoamericana - sueño de Bolívar y Alfaro-, la paz y la solidaridad con todos los pueblos de la tierra; $y$,

En ejercicio de nuestra soberanía, en Ciudad Alfaro, Montecristi, provincia de Manabí, nos damos la presente: CONSTITUCIÓN DE LA REPÚBLICA DEL ECUADOR.

Preámbulo de Constitución de Bolivia del año 2009:

En tiempos inmemoriales se erigieron montañas, se desplazaron ríos, se formaron lagos. Nuestra Amazonía, nuestro chaco, nuestro altiplano y nuestros llanos y valles se cubrieron de verdores y flores. Poblamos esta sagrada Madre Tierra con rostros diferentes, y comprendimos desde entonces la pluralidad vigente de todas las cosas y nuestra diversidad como seres y culturas. Así conformamos nuestros pueblos, y jamás comprendimos el racismo hasta que lo sufrimos desde los funestos tiempos de la colonia.

El pueblo boliviano, de composición plural, desde la profundidad de la historia, inspirado en las luchas del pasado, en la sublevación indigena anticolonial, en la independencia, en las luchas populares de liberación, en las marchas indígenas, sociales y sindicales, en las guerras del agua y de octubre, en las luchas por la tierra y territorio, y con la memoria de nuestros mártires, construimos un nuevo Estado. 
Un Estado basado en el respeto e igualdad entre todos, con principios de soberanía, dignidad, complementariedad, solidaridad, armonía y equidad en la distribución y redistribución del producto social, donde predomine la búsqueda del vivir bien; con respeto a la pluralidad económica, social, jurídica, política y cultural de los habitantes de esta tierra; en convivencia colectiva con acceso al agua, trabajo, educación, salud y vivienda para todos.

Dejamos en el pasado el Estado colonial, republicano y neoliberal. Asumimos el reto histórico de construir colectivamente el Estado Unitario Social de Derecho Plurinacional Comunitario, que integra y articula los propósitos de avanzar hacia una Bolivia democrática, productiva, portadora e inspiradora de la paz, comprometida con el desarrollo integral y con la libre determinación de los pueblos.

Nosotros, mujeres y hombres, a través de la Asamblea Constituyente y con el poder originario del pueblo, manifestamos nuestro compromiso con la unidad e integridad del país.

Cumpliendo el mandato de nuestros pueblos, con la fortaleza de nuestra Pachamama y gracias a Dios, refundamos Bolivia.

Honor y gloria a los mártires de la gesta constituyente y liberadora, que han hecho posible esta nueva historia.

Estos preámbulos hablan de una nueva fase del derecho constitucional en clave de Madre Tierra, incluso más allá del concepto de derechos de la naturaleza. Se apartan del preámbulo de la Constitución Política de 1991 (Colombia), tan marcadamente neoconstitucional, aunque leída como pionera de la transformación constitucional que se suscita tanto en Ecuador como en Bolivia.

Preámbulo de la Constitución Política de Colombia de 1991:

El pueblo de Colombia, en ejercicio de su poder soberano, representado por sus delegatarios a la Asamblea Nacional Constituyente, invocando la protección de Dios, y con el fin de fortalecer la unidad de la Nación y asegurar a sus integrantes la vida, la convevencia, el trabajo, la justicia, la igualdad, el conocimiento, la libertad y la paz, dentro de un marco jurídico, democrático y participativo que garantice un orden político, económico y social justo, y comprometido a impulsar la integración de la comunidad latinoamericana, decreta, sanciona y promulga la siguiente Constitución Política de Colombia.

Por supuesto, aunque dicha Constitución dista de los avances presentados en los textos políticos de 2008 y 2009, fue fundamental para avanzar en la construcción de un Estado que para la fecha de su promulgación se veía inviable y fallido. También, como ya se ha dicho, fue el punto de partida de las nuevas construcciones constitucionales en América Latina.

Aunque en medio de conflictos y coyunturas complejas (abandono, injusticia, discriminación), en los escenarios extraordinarios "del Sur" han emergido diversas corrientes jurídicas que tienen como horizonte la paz, la dignidad y la naturaleza, que aúnan tantas visiones del mundo $y$, en efecto, un abanico de nociones de justicia que han sido el detonante de diversos 
pluralismos jurídicos (ambientales, indígenas, sociales y de paz...), estas propuestas han sido difíciles de desarrollar, pues la mirada antropocéntrica, clásica y neoliberal-extractivista aún prevalece.

\section{LA TÍMIDA APUESTA AMBIENTAL DE LA CONSTITUCIÓN POLÍTICA DE 1991, EN CLAVE DE NEOCONSTITUCIONALISMO}

La temerosa apuesta de la Constitución Política de 1991 en materia ambiental puede tener diversas explicaciones. Para entenderlo, hay que recordar las características del denominado constitucionalismo andino o nuevo constitucionalismo latinoamericano. Según RAMIRO ÁVILA, la Constitución de Montecristi tiene seis instituciones que no tienen origen en el constitucionalismo liberal ni en la tradición constitucional de América Latina. La gran originalidad, según el profesor ecuatoriano, es que por primera vez estas características se plasmaron en textos constitucionales, precisamente para el caso de Ecuador y Bolivia, así como los desarrollos jurisprudenciales audaces del constitucionalismo en Colombia y la justicia comunitaria para el caso de Perú:

[...] Plurinacionalidad, la pachamama, el sumak kawsay, la democracia comunitaria, la justicia indígena y la interculturalidad. Estas incipientes instituciones marcan una diferencia sustancial y profunda en el constitucionalismo latinoamericano, que suelen pasar desapercibidas, en particular, entre los juristas y los constitucionalistas ${ }^{4}$.

Esta nueva forma de leer el derecho va más allá del mundo tradicional y ordinario. La introyección del pluralismo jurídico y de todas estas nuevas categorías solamente pueden ser explicadas, aprendidas y reconstruidas en clave de Sur. Estas nuevas lógicas permiten reconocer diversas nacionalidades, asimetrías, sistemas jurídicos, autonomías, nuevas formas de concebir el "desarrollo", la felicidad y las relaciones entre el hombre y la naturaleza.

Por su parte, las características del denominado neoconstitucionalismo están presentes en las nuevas constituciones, a manera de hibridez, aunque matizadas o mutadas conforme el contexto. Para el caso colombiano, esta impronta hace de las suyas en la Constitución Política de 1991. Este proceso, de comienzos de los noventa, tiene un contexto que justifica su marca liberal y social, bastante revolucionaria y de avanzada para la época. De hecho, VICIANO y MARTÍNEZ DALMAU $^{5}$ la tildan de pionera en materia de nuevo constitucionalismo latinoamericano. Un texto que encontró en la pluma de algunos jueces constitucionales una lectura más amplia y de sentido plural que ha marcado al constitucionalismo tanto de América Latina como del mundo.

La Constitución inicial o de 1991, que ha tenido más de cuarenta reformas a la fecha ${ }^{6}$, algunas de ellas bien alejadas del espíritu inicial del constituyente primario, presenta en su seno la

\footnotetext{
${ }^{4}$ ÁVILA, R., Neoconstitucionalismo transformador. El Estado y el derecho en la constitución de 2008. Abya Yala / Universidad Andina Simón Bolívar / Fundación Rosa Luxemburg, Quito, 2011, págs. 27-32.

5 VICIANO PASTOR, R.; MARTÍNEZ DALMAU, R., “La Constitución democrática, entre el neoconstitucionalismo y el nuevo constitucionalismo", El Otro Derecho, núm. 48, pp. 63-84, 2013.

6 VELÁSQUEZ, C., ¿Qué tan pisoteada ha sido la Constitución del 91? KienyKe, 17 de febrero de 2019.
} 
contradicción propia de la mayoría de las constituciones en América Latina: modelo económico social y neoliberal, lo cual explica las innumerables tensiones y conflictos existentes. Dicho texto contiene los elementos propios del Estado de derecho, por supuesto marcados por las características atinentes al Estado constitucional y social de derecho: fortalecimiento de la democracia, enfoques participativos, reconocimiento del pluralismo jurídico, identificación de espacios pluriétnicos, aparte de los propios del mundo neoconstitucional: constitución normativa y vinculante, que además condiciona todo el ordenamiento jurídico, eficacia y aplicación directa del texto constitucional; acciones constitucionales, tribunal constitucional de cierre, control de constitucionalidad y últimamente de convencionalidad; principios, valores, reglas y ponderación; rigidez constitucional y conexión entre derecho y moral ${ }^{7}$.

Características que no logran identificar con plenitud los seis elementos señalados por ÁVILA para tener las condiciones de constitucionalismo andino. Aun así, un texto fascinante por las dificultades en que se produce y por significar una transformación en la calidad de vida de millones de personas, además de abrir los espacios para la construcción de democracia y de paz, todavía en ciernes y de difícil concreción y completitud.

El punto de inflexión con el positivismo legalista se produjo con la Constitución Política de 1991 que, a decir verdad, fue más un tratado de paz que otra "carta de batalla" . Como la mayoría de las constituciones de finales del siglo XX y comienzos del siglo XXI, muchos venenos se inocularon en estos momentos constitucionales aupados bajo la crisis del modelo económico.

Para el caso colombiano, se sostiene que el asunto del modelo económico fue la máxima causa del cambio institucional; los demás hechos fueron utilizados para ambientar el momento, y por ello la nueva Carta Constitucional se caracterizó por incluir "las distintivas del modelo neoliberal" "Quizás esta sea una de las razones de las tímidas incursiones del criterio ambiental y antropocéntrico de esta nueva normativa. También es cierto que el momento histórico todavía no daba para tamaños desafíos y construcciones constitucionales en lógica andina.

Recuperado de https://www.kienyke.com/politica/reformas-constitucion-1991.

7 PRIETO SANCHÍS, L., "Neoconstitucionalismo y ponderación judicial”, en Neoconstitucionalismo(s), (ed. Miguel Carbonell), Madrid: Trotta, 2003; BENAVIDES ORDÓÑEZ, J., "Neoconstitucionalismo, nuevo constitucionalismo latinoamericano y procesos constituyentes en la región Andina. Ius Humani", Revista de Derecho, núm. 5, 2016, pp. 173-188; AA.VV, "El nuevo constitucionalismo latinoamericano", The Domocracy Papers No. 5, Trabajo presentado en panel Congreso 2012 de LASA (Latin American Studies Association), 2012; GIL RENDÓN, R., "El neoconstitucionalismo y los derechos fundamentales", Quid iuris (Chihuahua), núm. 12, 2011, 2011, pp. 43-51.

${ }^{8}$ Expresión ingeniada por el jurista y profesor VALENCIA VILLA, para referirse a las diferentes constituciones de Colombia que, como dice en el texto El derecho de los jueces, "han tenido siempre algo en común: la dependencia y la manipulación a las que son sometidas según las conveniencias y los intereses del gobierno de turno, convirtiéndose así en verdaderas fichas de estrategia utilizadas como cartas de batalla". VALENCIA VILLA, H., Cartas de Batalla, Bogotá: Panamericana, 2010.

${ }^{9}$ AHUMADA, C., El modelo neoliberal y su impacto en la sociedad colombiana, El Áncora, Bogotá, 2002, pág. 196. 
La Constitución de 1991 tiene elementos del constitucionalismo liberal, social y neoconstitucional, pero en la pluma de los jueces dichas apuestas se han transformado en interesantes herejías constitucionales y algunos pronunciamientos muy propios del Sur y de nuevas epistemologías.

Este modelo constitucional inspiró la creación de diversas clases de lecturas y justicias: las sentencias herejes ${ }^{10}$, lo cual ya habla bien del texto y del nuevo ejercicio hermenéutico (dosis personal, eutanasia, ley de cuotas, los derechos de los niños, etc.). Asimismo, el tema de la justicia constitucional indígena y de sus territorios, hoy, por ejemplo, en proceso de reafirmación territorial, esto es, de los viejos resguardos a verdaderas entidades territoriales (así sea de manera transitoria, tal como dispone el Decreto No. 1953 de 2014) y las prerrogativas territoriales que esta situación conlleva en materia de distribución de competencias, participación en las transferencias intergubernamentales y su incidencia en el mejoramiento de nivel de vida y administración propia o autogobierno. Además del reconocimiento de la jurisdicción indígena, tan respetuosa de las lógicas ancestrales y culturales, pero tan ligada a la lectura y cierre del Texto Político y constitucional ${ }^{11}$.

En general, el modelo constitucional de raigambre participativo, con total afinidad histórica y cultural con el modelo de Estado social y democrático de derecho, se ha convertido en una forma de reivindicar la voz de los pueblos que alguna vez fueron reducidos por la colonización (paradigmáticas sentencias, al unísono de diversos artículos constitucionales (2, 7, 40 y 330), y del Convenio 169 de la OIT (que versa sobre pueblos indígenas y tribales), se han proferido en pro de los derechos de las comunidades indígenas y demás grupos étnicos cuando ejercicios de democracia local, verbigracia, la consulta popular, han sido conculcados).

No existe una mención expresa al tema de los derechos de la naturaleza en la Constitución Política de 1991, ni en el preámbulo ni en los artículos iniciales de la Constitución que señalan los grandes principios fundamentales. Sin embargo, en el artículo $8^{\circ}$ del Texto Constitucional se lee: "Es obligación del Estado y de las personas proteger las riquezas culturales y naturales de la Nación". Más adelante se habla de los derechos sociales, económicos y culturales, de manera especial, se lee el artículo 49 que dispone sobre la responsabilidad del Estado en la organización, dirección y reglamentación de la prestación de los servicios de salud de los habitantes y de saneamiento ambiental conforme a los principios de eficiencia, universalidad y solidaridad.

También reposa un capítulo especial dedicado al tema de los derechos colectivos y del ambiente, en el cual se resalta que todas las personas tienen derecho a gozar de un ambiente sano y la participación de la comunidad en las decisiones que puedan afectarlo. Además del deber del Estado de proteger la diversidad e integridad del ambiente, la conservación de áreas de especial importancia ecológica y el fomento de la educación para el logro de estos fines

\footnotetext{
${ }^{10}$ GAVIRIA DÍAZ, C., Sentencias. Herejías Constitucionales, D.F.: Fondo de Cultura Económica, México, 2002.

${ }^{11}$ Otro aspecto trascendental ha sido el desarrollo de la figura de la consulta previa: derecho fundamental que les asiste a las comunidades indígenas de decidir en pleno ejercicio de la democracia participativa sobre las medidas legislativas o administrativas que puedan afectarlas en sus derechos e identidad originaria.
} 
como una responsabilidad del Estado (artículo 79). También señala como una responsabilidad de este, el de realizar una planificación para efectos del manejo y aprovechamiento de los recursos naturales, con miras a garantizar su desarrollo sostenible, conservación, restauración o sustitución. Esto, aparte de su papel de prevención y control de los factores de deterioro ambiental e imposición de sanciones legales y exigencia de reparación de los daños causados. Así como la cooperación con otras naciones, tal como lo señala el texto constitucional en su artículo 80, para la protección de los ecosistemas situados en las zonas fronterizas.

Se adicionan otros artículos sobre la prohibición de fabricación, importación, posesión y uso de armas químicas, biológicas y nucleares, así como la introducción al territorio nacional de residuos nucleares, y su utilización, de acuerdo con el interés nacional (artículo 81 de la Constitución Política) y el de velar por la integridad del espacio público y por su destinación al uso común, el cual prevalece sobre el interés particular (artículo 82). Finalmente, se señala que las entidades públicas participarán en la plusvalía que genere su acción urbanística y regularán la utilización del suelo y del espacio aéreo urbano en defensa del interés común. Estos artículos deberán leerse en clave de principios, derechos y del bloque de constitucionalidad, consagrado en el artículo 93 del Texto Político.

Como se puede observar, la Constitución Política de Colombia es diferente a las de Ecuador y Bolivia. Hace parte del reconocimiento del tema ambiental propio de finales del siglo XX. Es un texto tradicional en lógicas de derecho ambiental, lo que ha sido tildado como constitucionalismo ecológico o ambiental, que, si bien procede de una necesidad de reivindicación y emancipación de la cultura y la naturaleza, aún es demasiado antropocéntrico, o al menos lo es en comparación con los compromisos ecocéntricos de otras constituciones o la transformación del paradigma epistemológico en clave de $\operatorname{Sur}^{12}$.

\section{CON PEDAZOS DE ESTRELLAS INVENTAMOS MUNDOS. LA CONSTRUCCIÓN DEL DERECHO DE LA NATURALEZA EN COLOMBIA}

Más de veinte años de construcción constitucional, ambiental, de conflictos, de reivindicaciones sociales y de nuevos rumbos del derecho en el mundo han incidido en la creación de una pluma diferente para los jueces o los operadores jurídicos, actores territoriales, comunidades y movimientos. La lectura de diversos sectores en materia ambiental ha mutado en Colombia. Surgen interpretaciones plurales que han reconocido nuevas categorías, todas construidas en una hermenéutica de conciliación entre el hombre y la naturaleza. Por supuesto, dichas

\footnotetext{
${ }^{12}$ Sin embargo, "dignos desarrollos por vía jurisprudencial hoy se deben celebrar. Antes las tutelas provenían de las comunidades; hoy son las propias multinacionales (caso Mansarovar Energy Colombia Ltd.) quienes acuden a esta acción constitucional para dar por no válida la consulta popular realizada por los municipios que se niegan a la exploración de hidrocarburos en sus territorios". ESTUPIŃNÁN ACHURY, L.; ROMO, M. "La construcción de la justicia transicional de cierre de guerra en Colombia: una lectura en clave de Sur y pluralismo", Constitucionalismo transicional en Colombia: el derecho a la paz como un deber de construcción dialógica, (ed. Estupiñán Achury), Universidad Libre, Bógota, 2018, pág.29; cfr. PALOMARES, J., "Duro tatequieto a las empresas mineras: debate hoy en la Corte Constitucional. El Espectador, 12 de abril de 2018. Recuperado de https://www.elespectador.com/noticias/judicial/duro-tatequieto-las-empresas-mineras-debate-hoy-en-la-corteconstitucional-articulo-749590.
} 
lecturas son problemáticas para muchos, pero tranquilizadoras para otros, al cambiar el ritmo antropocéntrico por el ecocéntrico, o mejor, por el reconocimiento de la Madre Tierra y el papel depredador de uno de sus hijos: los animales racionales.

Actores políticos territoriales como los actuales (para la fecha de entrega de este capítulo) gobernadores de los departamentos (niveles intermedios de Colombia) de Nariño (Camilo Romero) y Boyacá (Carlos Amaya) han realizado un pacto político, en el marco del bicentenario, para declarar la naturaleza como sujeto de derechos, "expedir decretos [...] para garantizar los derechos a los campesinos, prohibir el asbesto y los plásticos de un solo uso en la contratación pública" ("Gobernadores firman pacto para declarar a la naturaleza como sujeto de derechos”, 2019), así como el icopor. Este es un hecho insólito en la construcción de un constitucionalismo distinto que no va a dar vuelta atrás, pero que genera demasiadas resistencias.

También el papel de la comunidad, por no hablar en este documento del trascendental ejercicio democrático que han realizado las comunidades étnicas en desarrollo de la consulta previa y la protección de sus territorios ancestrales ${ }^{13}$.

Las comunidades, arropadas por el principio de la autonomía territorial y la democracia participativa, han impulsado más de 41 consultas populares, de las cuales, según datos de la Registraduría Nacional, 10 corresponden a consultas populares relacionadas con el tema minero y de vocación de sus territorios en el marco de la democracia participativa. Consultas que han rechazado la minería en sus territorios y que hoy han sido desvirtuadas por la Corte Constitucional, a partir de un fallo que desconoce el alcance del principio de la autonomía territorial, la democracia participativa y la posibilidad que tienen los pueblos de proteger sus vocaciones territoriales, el agua, el medio ambiente, la seguridad alimentaria y los derechos de la naturaleza. Por supuesto, bajo una lectura amplia del texto político de 1991. Al respecto, GIRALDO realizó una excelente síntesis ${ }^{14}$ :

Preocupante sentencia SU-095/2018 de la Corte Constitucional colombiana que revoca una decisión de un tribunal que declaraba constitucional una pregunta realizada en el marco de una consulta popular en la que se interrogaba a los pobladores de un municipio si estaban o no de acuerdo con la realización de actividades mineras en su territorio. Lo más complejo es que el caso llega al Alto Tribunal por una tutela interpuesta contra esta providencia emitida por el tribunal administrativo por parte de una multinacional: Mansarovar Energy Colombia Ltd.

En esta sentencia decidió la Corte Constitucional que, pese a la autonomía territorial, no era competencia de los entes territoriales decidir mediante mecanismos de participación ciudadana si se realizan o no actividades de extracción minera, puesto que el titular de los derechos sobre el subsuelo es el Estado, por ende, compete a las autoridades del orden

\footnotetext{
${ }^{13}$ RODRÍGUEZ, G. A., De la consulta previa al consentimiento libre, previo e informado a pueblos indígenas en Colombia, Ibáñez, Bogotá, 2014.

${ }^{14}$ GIRALDO GÓMEZ, J., “Consultas populares mineras, ¿en qué quedó la autonomía territorial y la democracia participativa?" Ámbito Jurídico. 17 de noviembre de 2018. Recuperado de https://www.ambito juridico.com/noticias/informe/administrativo-y-contratacion/consul tas-populares-mineras-en-que-quedo-la
} 
nacional decidir qué hacer con ellos.

"En lo que se refiere a las llamadas restricciones competenciales del pueblo en la consulta popular, la Corte Constitucional ha señalado de forma expresa la imposibilidad de realizar consultas populares sobre asuntos ajenos a las competencias de las autoridades territoriales o sobre aquellos que tengan incidencia en los asuntos nacionales o departamentales" (Corte Constitucional, Sentencia SU-095/2018). Este pronunciamiento es antecedido por otras sentencias más generosas con el uso y el alcance del principio de la autonomía territorial, un giro democrático que venía dando la Corte desde el año 2014 ${ }^{15}$. Sin embargo, el embrujo o el amor por lecturas más amplias y democráticas del principio de autonomía no duró más de cuatro años. La manecilla del reloj, tan vulnerable, giró al extremo centralizador del mundo extractivista, y los pueblos, por ahora, han quedado desprotegidos para la protección de sus territorios. El mercado en tensión con visiones más amables de protección de los territorios y la naturaleza.

A pesar de este pronunciamiento, no se puede desconocer que precisamente los jueces constitucionales son quienes están desempeñando un papel protagónico en lo atinente al reconocimiento de los derechos de la naturaleza, dándole incluso el estatus de sujeto de protección a cargo del Estado a entidades que, a pesar de que hace años se salvaguardan constitucionalmente, no habían dejado de tratarse como objetos a disposición de los humanos. En la Sentencia T-622/2016, por ejemplo, se revolucionó la forma clásica, en tanto antropocéntrica, de concebir solo "al hombre" como sujeto de derechos al ampliar dicha categoría al río Atrato.

Esta sentencia, por cierto, emblemática en América Latina, guarda correspondencia con el caso del río Vilcabamba ${ }^{16}$ : antecedente más importante de los derechos constitucionales de los ríos. En la Sentencia del río Atrato se tutelaron los derechos fundamentales a la vida, la salud, el agua, la seguridad alimentaria, al medio ambiente sano, la cultura y el territorio de las comunidades étnicas (Corte Constitucional, T-622/2016).

\footnotetext{
15 "Sobre las tensiones que se presentan entre la competencia que tiene la entidad municipal para ordenar el desarrollo de su territorio y, más concretamente, la que tiene el concejo o la corporación político-administrativa de la entidad local para reglamentar los usos del suelo frente a la competencia que tiene el Estado sobre la exploración y explotación minera, la Corte Constitucional condicionó la constitucionalidad del artículo 37 del Código de Minas, "en el entendido que, en desarrollo del proceso por medio del cual se autorice la realización de actividades de exploración y explotación minera, las autoridades competentes del nivel nacional deberán acordar con las autoridades territoriales concernidas las medidas necesarias para la protección del ambiente sano y, en especial, de sus cuencas hídricas, el desarrollo económico, social, cultural de sus comunidades y la salubridad de la población, mediante la aplicación de los principios de coordinación, concurrencia y subsidiariedad previstos en el artículo 288 de la Constitución Política". (Corte Constitucional. Sentencia C-123 de 2014. Magistrado ponente: Alberto Rojas Ríos). No obstante, valga precisar que por medio de la Sentencia C-273 de 2016, la Corte Constitucional declaró inexequible el artículo 37 del Código de Minas. Según la Corporación, la prohibición legal citada desconocía la reserva de ley orgánica por tratarse de una norma contenida en una ley ordinaria que se refiere a la distribución de competencias entre la nación y las entidades territoriales, en este caso, la reglamentación del uso del suelo" (Estupiñán, 2018, p. 219). Así mismo, la Corte Constitucional reforzó este precedente en materia de garantía del principio de autonomía territorial con la sentencia T-445 de 2016.
}

${ }^{16}$ Corte Provincial de Loja, Sala Penal. Acción de Protección No. 11121-2011-0010. 
Para el Alto Tribunal, la denominada

Constitución Ecológica [...] está muy lejos de ser una simple declaración retórica en la medida en que comprende un preciso contenido normativo integrado por principios, derechos fundamentales y obligaciones a cargo del Estado.

\section{$[\ldots]$}

De este modo, la Constitución y la jurisprudencia constitucional, en armonía con los instrumentos internacionales, se han decantado en favor de la defensa del medio ambiente y de la biodiversidad, en beneficio de las generaciones presentes y futuras, consagrando una serie de principios y medidas dirigidos a la protección y preservación de tales bienes jurídicos, objetivos que deben lograrse no solo mediante acciones concretas del Estado, sino con la participación de los individuos, la sociedad y los demás sectores sociales y económicos del país. (T-622/2016)

Esta sentencia reconoce "al río Atrato, su cuenca y afluentes como una entidad sujeto de derechos a la protección, conservación, mantenimiento y restauración a cargo del Estado y las comunidades étnicas". Ordenó al Gobierno nacional a ejercer tutoría y representación legal de los derechos del río, "restablecer los derechos de las comunidades étnicas que habitan la cuenca del río Atrato, especialmente en lo que tiene que ver con la recuperación de su cultura, participación, territorio, identidad, modo de vida y actividades productivas, incluida la pesca, la caza, la agricultura, la recolección de frutos y la minería artesanal". Estas medidas de protección, entre otras, para el Estado, entidades territoriales, etc., con miras a lograr el restablecimiento de derechos fundamentales y la protección de la naturaleza.

A este pronunciamiento se le agrega la connotación como sujeto de derechos que la Corte Suprema de Justicia (Sala de Casación Civil, STC 4360-2018) le dio a la selva amazónica, víctima de intensa deforestación que se aproxima al peligroso punto de "no retorno", luego de reafirmar su calidad de "pulmón del mundo" y "eje ambiental del planeta" (Estupiñán y Romo, 2018, p. 31).

La sentencia de la Corte Suprema de justicia culpa a la hegemonía del desarrollo humano como responsable del gran deterioro a la naturaleza y de la correspondiente reparación de los daños. Solidaridad de especie con los no nacidos y solidaridad directa con la naturaleza por pertenecer a esta, y no al revés. Respetar la naturaleza implica respetarse a sí mismo por ser parte de esta. "La conservación de la Amazonía es una obligación nacional y global, se trata del principal eje ambiental existente en el planeta, por tal motivo se le ha catalogado como el "pulmón del mundo". Agrega: "Por tanto, en aras de proteger ese ecosistema vital para el devenir global, tal como la Corte Constitucional declaró al río Atrato, se reconoce a la Amazonía Colombiana como entidad, "sujeto de derechos", titular de la protección, de la conservación, mantenimiento y restauración a cargo del Estado y las entidades territoriales que la integran” (Corte Suprema de Justicia, Sala de Casación Civil, STC 4360-2018).

Estas sentencias, acordes a un Estado pluralista, en tanto reivindicador de la biodiversidad y proliferación de la cultura, han sido posibles por una constitución normativa que le apostó a la reconstrucción de un país que hasta entonces solo había conocido la violencia. Así pues, primero la Carta Política del 91 le abrió el camino a diversos proyectos de paz y pluralismo, 
luego los jueces y demás sectores se sumaron a tamaños propósitos de reinvención nacional y reconciliación con la naturaleza.

Pero lo ambiental para el caso colombiano debe ir más allá y ser cruzado con la paz, la autonomía territorial, los temas de consulta previa, los territorios indígenas, la protección del agua y la seguridad alimentaria frente a las lógicas extractivistas que imperan en el modelo económico colombiano y de la mayoría de los Estados de América Latina.

Por ello, también se resalta en este escrito la relación que ya se observa en la construcción de la justicia transicional entre conflicto y Madre Tierra (en el marco de la Justicia Especial para la Paz). A propósito de esto, la Unidad de Investigación y Acusación -UIA- reconoció que en el marco del "conflicto armado colombiano se adelantaron múltiples acciones que, de manera intencional, accidental o negligente, ocasionaron daños y alteraciones sobre los ciclos naturales de los ecosistemas, con efectos temporales o permanentes" ${ }^{17}$. Una vez reconocido esto, ÁLVAREZ SANTOYO, director de la UIA, señaló lo siguiente: "La Unidad de Investigación y Acusación está comprometida con el reconocimiento del ambiente como víctima silenciosa del conflicto y con la búsqueda de mecanismos para su reparación efectiva, propendiendo por garantizar la no repetición"18.

Por último, valga señalar que, en Colombia, la protección de la naturaleza "se paga con la vida"19, tal como lo señala Francia Márquez, premio Goldman, considerado como el Nobel ambiental. Si en cualquier país y contexto pensar en la protección de la naturaleza o la naturaleza como sujeto de derechos, ya constituye una herejía contra el modelo económico y el mercado, en Colombia, además, se convierte en un tema complejo cruzado con el conflicto armado, aún no superado, la economía ilegal y de la guerra, los territorios cooptados por mafias y corrupción y la entrega "legal" del territorio a multinacionales en clave de explotación y extractivismo, esto es, una nueva fase de colonización.

\section{BIBLIOGRAFÍA}

AA.VV., "El nuevo constitucionalismo latinoamericano", The Domocracy Papers No. 5, Trabajo presentado en panel Congreso 2012 de LASA (Latin American Studies Association), 2012.

AHUMADA, C., El modelo neoliberal y su impacto en la sociedad colombiana, El Áncora, Bogotá, 2002.

\footnotetext{
17 Unidad de Investigación y Acusación de la JEP (2019). Unidad de Investigación y Acusación de la JEP, "reconoce como víctima silenciosa el medio ambiente" (Boletín de prensa. Comunicado 009). Recuperado de: https://www.jep.gov.co/SiteAssets/Paginas/UIA/sala-de-prensa/Comunicado\%20UIA\%20-\%20009.pdf).

18 Ibidem.

${ }^{19}$ La defensa del territorio en Colombia se paga con la vida. (2018, 1 de noviembre). El País. Recuperado de https://elpais.com/elpais/2018/10/25/planeta_futuro/1540468269_209574.html
} 
ÁVILA, R., Neoconstitucionalismo transformador. El Estado y el derecho en la constitución de 2008. Abya Yala / Universidad Andina Simón Bolívar / Fundación Rosa Luxemburg, Quito, 2011.

BENAVIDES ORDÓÑEZ, J., "Neoconstitucionalismo, nuevo constitucionalismo latinoamericano y procesos constituyentes en la región Andina. Ius Humani”, Revista de Derecho, núm. 5, 2016, pp. 173-188.

ESTUPIÑÁN ACHURY, L., "Modelos territoriales para Estados plurales y diversos. El caso de Colombia". En AA.VV., La cuestión territorial a debate: España y Colombia, Universidad Libre, Bogotá, 2018, pág. 215-238.

ESTUPIÑÁN ACHURY, L.; ROMO, M. "La construcción de la justicia transicional de cierre de guerra en Colombia: una lectura en clave de Sur y pluralismo", En Liliana Estupiñán Achury (editora). Constitucionalismo transicional en Colombia: el derecho a la paz como un deber de construcción dialógica, (ed. Estupiñán Achury), Universidad Libre, Bógota, 2018, págs.. 21-66.

GAVIRIA DÍAZ, C., Sentencias. Herejías Constitucionales, D.F.: Fondo de Cultura Económica, México, 2002.

GIL RENDÓN, R., "El neoconstitucionalismo y los derechos fundamentales”, Quid iuris (Chihuahua), núm. 12, 2011, 2011, pp. 43-51.

GIRALDO GÓMEZ, J., “Consultas populares mineras, ¿en qué quedó la autonomía territorial y la democracia participativa?” Ámbito Jurídico. 17 de noviembre de 2018. Recuperado de https://www.ambito juridico.com/noticias/informe/administrativo-ycontratacion/consul tas-populares-mineras-en-que-quedo-la

LONDOÑO TORO, B., "La constitución de 1991 y los indígenas”, Credencial Historia, núm. 146. Recuperado del sitio de internet de la Red Cultural del Banco de la República: http://www.banrepcultural.org/biblioteca-virtual/credencial-historia/numero-146/laconstitucion-de-1991-y-los-indigenas

PALOMARES, J.,"Duro tatequieto a las empresas mineras: debate hoy en la Corte Constitucional. El Espectador, 12 de abril de 2018. Recuperado de https://www.elespectador.com/noticias/judicial/duro-tatequieto-las-empresas-minerasdebate-hoy-en-la-corte-constitucional-articulo-749590

PAVANI, G.; y ESTUPIÑÁN ACHURY, L., "Mutaciones del Estado Unitario en América Latina. Nuevos Rasgos Metodológicos para el Estudio de los Procesos de Descentralización", Plurinacionalismo y Centralismo: Tensiones del Estado Unitario en América Latina (ed. Giorgia Pavani y Liliana Estupiñán Achury) Bogotá: Ediciones Nueva Jurídica, 2017, págs. 101-159.

PRIETO SANCHÍS, L., "Neoconstitucionalismo y ponderación judicial”, en Neoconstitucionalismo(s), (ed. Miguel Carbonell), Madrid: Trotta, 2003. 
RODRÍGUEZ, G. A., De la consulta previa al consentimiento libre, previo e informado a pueblos indígenas en Colombia, Ibáñez, Bogotá, 2014.

VALENCIA VILLA, H., Cartas de Batalla, Bogotá: Panamericana, 2010.

VELÁSQUEZ, C., ¿Qué tan pisoteada ha sido la Constitución del 91? KienyKe, 17 de febrero de 2019. Recuperado de https://www.kienyke.com/politica/reformas-constitucion-1991

VICIANO PASTOR, R.; MARTÍNEZ DALMAU, R., "La Constitución democrática, entre el neoconstitucionalismo y el nuevo constitucionalismo", El Otro Derecho, núm. 48, pp. 63-84, 2013.

WOLKMER, A., Pluralismo jurídico fundamentos de una nueva cultura del derecho, $2^{\mathrm{a}}$ ed. Madrid: Dykinson, 2018. 